\title{
Inhibition of calcineurin by cyclosporine A exerts multiple effects on human melanoma cell lines HT168 and WM35
}

\author{
TAMÁS JUHÁSZ ${ }^{1}$, CSABA MATTA ${ }^{1}$, GÁBOR VERESS ${ }^{1}$, GEORGINA NAGY ${ }^{2}$, ZSOLT SZÍJGYÁRTÓ ${ }^{3}$, \\ ZSANETT MOLNÁR ${ }^{3}$, JÁNOS FODOR ${ }^{4}$, RÓZA ZÁKÁNY ${ }^{1}$ and PÁL GERGELY ${ }^{3}$ \\ ${ }^{1}$ Department of Anatomy, Histology and Embryology, ${ }^{2}$ Department of Dermatology, ${ }^{3}$ Cell Biology and Signalling Research \\ Group of the Hungarian Academy of Sciences, Department of Medical Chemistry and ${ }^{4}$ Department of Physiology \\ Medical and Health Science Centre, University of Debrecen, Hungary
}

Received September 19, 2008; Accepted November 21, 2008

DOI: 10.3892/ijo_00000225

\begin{abstract}
The immunosuppressant cyclosporine A (CsA) is a specific pharmacological inhibitor of calcineurin, the $\mathrm{Ca}^{2+}$-calmodulin activated phospho-Ser/Thr-specific protein phosphatase. Although calcineurin-inhibiting compounds are applied for local treatment of psoriasis or atopic dermatitis in dermatological practice, little is known about the functions of calcineurin in epidermis-derived malignancies. We investigated the effects of CsA on two human melanoma cell lines, the metastasis forming HT168 and WM35 established from an RGP primary lesion. CsA of $2 \mu \mathrm{M}$ lowered the enzyme activity by $50 \%$ and caused elevation in both mRNA and protein expression of calcineurin. Cell proliferation was diminished, as well as the cellular morphology and the actin organization were altered in both cell lines. CsA increased cell death moderately in both cell lines and reduced the metabolic activity of HT168 cells, but not that of WM35 cells. CsA also elevated the expressions of both Bcl-2 and ERK1/2. Fibronectin guided migration of HT168 cells was stimulated under the effect of CsA, while that of WM35 cells was reduced, moreover, HT168 cells switched from the expression of $B 3$ to $\beta 1$ integrin, but WM35 cells continued to express $B 3$. Based on our results we propose a multiple, partly malignancy-dependent role of calcineurin in these melanoma cell lines.
\end{abstract}

\section{Introduction}

Calcineurin or PP2B is a Ca-calmodulin activated phosphoSer/Thr-specific protein phosphatase, which was first detected in brain and skeletal muscle (1), and is best known as a key regulator of T-lymphocyte activation via dephosphorylation

Correspondence to: Dr Pál Gergely, Department of Medical Chemistry, Medical and Health Science Centre, University of Debrecen, Nagyerdei krt. 98, H-4032 Debrecen, Hungary E-mail: gpal@dote.hu

Key words: calcineurin, cyclosporine A, migration, actin organization, integrins, apoptosis, ERK1/2, Bcl-2 and consequent nuclear translocation of the transcription factor: Nuclear Factor of Activated T-lymphocytes (NFAT) $(2,3)$.

Pharmacological inhibitors of calcineurin, such as cyclosporine A (CsA), tacrolimus or pimecrolimus recently became popular in the dermatological practice for topic treatment of diseases of skin which accompany activation of T-lymphocytes, e.g. atopic dermatitis (4). Local application of these compounds have no significant side effects (5), but it is reported that long-term systemic application of calcineurin inhibitors as immunosuppressants following organ transplantations may increase the incidence of skin tumours, particularly squamous cell carcinoma (6).

Some physiological roles of calcineurin played in keratinocytes have been reported recently. It serves as a factor in the regulation of the terminal differentiation of keratinocytes (7) and it modulates the DNA repair following UV irradiation (8). Application of calcineurin inhibitors for the treatment of hypopigmentary skin disorders has also been suggested (9), but the investigation of the physiological role of calcineurin in the biology of melanocytes, the pigment producing cells of epidermis, has just started (10).

Melanocytes develop from neural crest during embryonic life and have intense ability of migration in this period. Differentiated melanocytes regularly do not proliferate or migrate in adult epidermis and are under tight control of keratinocytes (11). Cutaneous malignant melanoma originating from the melanocytes of the epidermis, is a highly malignant variant of skin tumours with a very poor prognosis if it starts to form metastases, since melanoma cells are highly resistant to any kind of conventional chemotherapy or irradiation. The results of experiments carried out during the last two decades revealed that malignant transformation of melanocytes is associated with overexpression and/or overactivation of various Ser/Thr-specific protein kinases, e.g. protein kinase C (12), protein kinase A (13) or MAP kinases (14). The importance of these signal transduction molecules in the ethiopathogenesis of melanoma is underlined by the fact that pharmacological inhibitors of these enzymes are promising therapeutic drugs of this malignancy (15-17). Although the presumed role of Ser/Thr-protein phosphatases in the altered signal transduction pathways is beyond question, 
little is known about the function of these enzymes in the cellular mechanisms of melanoma cells. As changes of the intracellular $\mathrm{Ca}$-concentration are reported to be involved in the different cellular functions of melanoma cells such as migration (18) or cellular viability (19), it seems likely that calcineurin may play a role in the regulation of these processes.

The aim of our study was to investigate the possible role(s) of calcineurin in the major cellular functions of two human melanoma cell lines; one of which (HT168) represents an experimental model of a highly metastatic melanoma (20), while the other (WM35) was isolated from a radial growth phase (RGP) primary lesion (21), and might be a good model of a less malignant, non-metastatic type of this malignancy. We report herein that inhibition of calcineurin by CsA caused different alterations in the morphology, actin organization, proliferation, viability, as well as fibronectin guided migration of the two melanoma cell lines. Furthermore, we found that CsA increased both the expression and the phosphorylation of ERK1/2, and it also elevated the protein level of Bcl-2 and modulated the $B 3$ and $B 1$ integrin expression pattern of melanoma cells. Based on our findings we suggest a multiple role of calcineurin in melanoma cells which partly depends on the stage of malignancy.

\section{Materials and methods}

Cultures of melanoma cell lines. Human melanoma cell line HT168 was selected from A2058 cell line according to its metastasis formation in immunosuppressed mice (20), while WM35 was established from a primary cutaneous melanoma of radial growth phase (21). Both cell lines were provided by Dr J. Tímár (National Institute of Oncology, Budapest, Hungary). Cells were cultured in RPMI culture medium (Sigma, Budapest, Hungary) supplemented with 5\% foetal bovine serum (HyClone, South Logan, UT), 2 mM L-glutamine (Gibco, Gaithersburg, MD), penicillin (100 units/ml) and streptomycin $(100 \mu \mathrm{g} / \mathrm{ml})$ at $37^{\circ} \mathrm{C}$ in the presence of $95 \%$ air and $5 \% \mathrm{CO}_{2}$ atmosphere and $80 \%$ humidity in $25 \mathrm{~cm}^{2}$ flasks (Orange Scientifique, Braine-l'Alleud, Belgium) until approximately $70 \%$ confluence. Activity of calcineurin was inhibited by continuous application of $2 \mu \mathrm{M}$ CsA (Sigma) starting 2 days before confluence.

Light microscopical morphology analysis. Melanoma cells of different experimental groups were cultured on the surface of rectangular coverglasses (Menzel-Gläser, Menzel GmbH, Braunschweig, Germany) placed into Petri dishes. After rinsing, cells were fixed in a 4:1 mixture of absolute ethanol and $40 \%$ formaldehyde, stained with haematoxylin and eosin (Sigma) and mounted in gum arabic. Photomicrographs of cells were taken using a Spot Advanced camera on a Nikon Eclipse E800 microscope (Nikon Corporation, Tokyo, Japan).

Immunocytochemistry. For immunocytochemistry cells were cultured on the surface of rectangular coverglasses as described above. For calcineurin immunocytochemistry cells were fixed in Sainte-Marie solution (22) and washed in 70\% ethanol. After rinsing in PBS, cells were blocked with PBS supplemented with $1 \%$ bovine serum albumin, then incubated in a polyclonal Pan-calcineurin A antibody (Cell Signaling Technology, Danvers, MA) at a dilution of 1:400 at $4^{\circ} \mathrm{C}$ overnight. For visualisation of the primary antibody, FITCconjugated anti-rabbit secondary antibody (Vector Laboratories, Peterborough, UK) was used at a dilution of 1:1000. Cultures were mounted in Vectashield Hard Set mounting medium (Vector Laboratories) containing DAPI to visualise the nuclei. To demonstrate actin, cells were fixed in acetone at $-20^{\circ} \mathrm{C}$ for $20 \mathrm{~min}$. After washing at room temperature with calcium magnesium-free phosphate buffer solution (CMFPBS), TRITC-Phalloidin (Sigma) was applied at a dilution of 1:300 (23). Cultures were viewed by fluorescence microscopy (Nikon Eclipse E800, Nikon Corporation). All images were acquired using constant camera settings to allow comparison of staining intensities.

Migration assay. Cells were washed twice in CMF-PBS, harvested with $0.25 \%$ trypsin (Sigma) and resuspended in RPMI in a density of $2 \times 10^{5}$ cells $/ \mathrm{ml}$. Lower wells of Boyden chamber (Neuro Probe Inc., Gaithersburg, MD) were filled with $1 \mu \mathrm{l} / \mathrm{ml}$ human fibronectin (Sigma) dissolved in CMFPBS and covered with a polycarbonate filter (Neuro Probe Inc.) containing pores with a diameter of $3 \mu \mathrm{m}$. Cell suspension $(50 \mu \mathrm{l})$ was inoculated into the wells on the top of the membrane and the chamber was incubated for $3 \mathrm{~h}$ at $37^{\circ} \mathrm{C}$ in a humidified atmosphere $\left(5 \% \mathrm{CO}_{2}-95 \%\right.$ air $)$. Non-migrated cells were removed from the surface of the membrane and after fixation in methanol, migrated cells were stained with $1 \%$ toluidine blue (Sigma) dissolved in water (24). Membranes were air-dried and mounted with gum arabic. Absolute cell numbers were counted using a light microscope.

Measurement of apoptosis using flow cytometry. After $48 \mathrm{~h}$ of treatment with CsA, the amount of apoptotic cells was determined using an Annexin V DY647 kit (Central European Biosystems, Budapest, Hungary) (25) and the ratio of necrotic cells was measured after staining with propidium iodide (PI, Sigma). Untreated cells were used as control. After washing twice in CMF-PBS, cells were incubated in $10 \mu \mathrm{l}$ Annexin V DY647 and/or PI at room temperature for $10 \mathrm{~min}$. Before harvesting with $0.25 \%$ trypsin, cells were washed with Annexin V binding buffer or CMF-PBS. Cell pellets were resuspended in $1000 \mu 1 \mathrm{FACS}$ buffer (PBS supplemented with $1 \% \mathrm{BSA}$ and $0.05 \% \mathrm{NaN}_{3}$ ) and were analysed with a CyFlow ${ }^{\circledR}$ space Flow Cytometer (Partec GmbH, Münster, Germany). Annexin V DY647 was monitored at $670 \mathrm{~nm}$ and PI was detected at $430 \mathrm{~nm}$. Measurement lower threshold was set on cell-size particles. Analysis was performed using WinMDI 2.8 freeware (Joseph Trotter, http://facs.scripps.edu/). Quadrants of Annexin/PI density plots were set as follows: Annexin-/PI-; Annexin+/PI-; Annexin-/PI+; Annexin+/PI+ populations.

Measurement of cell proliferation with ${ }^{3} \mathrm{H}$-thymidine labelling and mitochondrial activity with MTT-assay. Medium containing $1 \mu \mathrm{Ci} / \mathrm{ml}{ }^{3} \mathrm{H}$-thymidine $(185 \mathrm{GBq} / \mathrm{mM}$ ${ }^{3} \mathrm{H}$-thymidine, Amersham Biosciences, Budapest, Hungary) was added to cells cultured in wells of 24-well plates for $16 \mathrm{~h}$ on 2 nd day of CsA treatment. After washing with PBS, 
proteins were precipitated with ice-cold $5 \%$ trichloroacetic acid for $20 \mathrm{~min}$. After washing with PBS again, cells were harvested using $0.25 \%$ trypsin for $30 \mathrm{~min}$ and collected with centrifugation at $2000 \mathrm{x} \mathrm{g}$. The pellet was resuspended in $10 \mu 1$ CMF-PBS and placed into wells of special opaque 96-well plates (Wallac, PerkinElmer Life and Analytical Sciences, Shelton, CT). The plates were placed in an exsiccator containing phosphorous pentoxide in order to absorb moisture. Prior to measurements, $50 \mu 1$ scintillation solution (MaxiLight; Hidex Ltd., Turku, Finland) was added to each well and radioactivity was counted by a liquid scintillation counter (Chameleon Microplate Reader, Hidex Ltd., Turku, Finland). For investigation of mitochondrial activity, cells were cultured in wells of 24-well plates and MTTassays were performed measuring the absorption at $570 \mathrm{~nm}$ (Chameleon Microplate Reader).

Determination of cytosolic free $\mathrm{Ca}^{2+}$ concentration. Measurements were performed on melanoma cell cultures with approximately $70 \%$ confluence using the calciumdependent fluorescent dye Fura-2 (TEFLabs, Inc. Austin, TX). Cell lines were transferred to $2 \mathrm{ml}$ fresh RPMI medium containing $10 \mathrm{ml}$ Fura-2-AM $(10 \mu \mathrm{M})$ and $4 \mu \mathrm{l}$ neostigmin $(0.3 \mathrm{nM})$ to inhibit extracellular choline esterases. After 60 min of incubation at $37^{\circ} \mathrm{C}$ in a $\mathrm{CO}_{2}$ incubator, cultures were washed twice in Tyrode's solution $(137 \mathrm{mM} \mathrm{NaCl}$, $5.4 \mathrm{mM} \mathrm{KCl}, 0.5 \mathrm{mM} \mathrm{MgCl}, 1.8 \mathrm{mM} \mathrm{CaCl}_{2}, 11.8 \mathrm{mM}$ Hepes, 1 g/l glucose, pH 7.4). Fura-2-loaded cells were placed on the stage of an inverted fluorescent microscope and viewed using a x40 oil immersion objective. Measurements were carried out in the above described Tyode's solution in a perfusion chamber using a dual wavelength monochromator (DeltaScan, Photon Technologies International, Lawrenceville, KY) equipment. Fluorescence was measured using excitation wavelengths of 340 and $380 \mathrm{~nm}$ and an emission wavelength of $510 \mathrm{~nm}$. Cytosolic free $\mathrm{Ca}^{2+}$ concentrations were calculated from the ratios of intensities $(\mathrm{R}=\mathrm{F} 340 / \mathrm{F} 380)$ as described (26).

Western blot analysis. Total cell lysates were examined by Western blot. Samples for SDS-PAGE were prepared by the addition of $100 \mu \mathrm{l}$ of 5-fold concentrated electrophoresis sample buffer (20 mM Tris- $\mathrm{HCl}$ pH 7.4, 0.01\% bromophenol blue dissolved in $10 \%$ SDS, $100 \mathrm{mM} \beta$-mercaptoethanol) to cell lysates and boiled for $10 \mathrm{~min}$. About $60 \mu \mathrm{g}$ of protein was separated by $7.5 \%$ SDS-PAGE gel for detection of ERK1/2, p-ERK1/2, calcineurin, Bcl2, integrin $B 1$, and integrin $B 3$. Proteins were transferred electrophoretically to nitrocellulose membranes. After blocking in 5\% non-fat dry milk in PBST (phosphate buffered saline with $0.1 \%$ Tween-20, 20 mM Na${ }_{2} \mathrm{HPO}_{4}, 115 \mathrm{mM} \mathrm{NaCl}$; pH 7.4), membranes were washed and exposed to the primary antibodies overnight at $4^{\circ} \mathrm{C}$. Polyclonal anti-ERK $1 / 2$ antibody (Sigma) in 1:750, monoclonal anti-diphosphorylated-ERK1/2 (pERK1/2) antibody (Sigma) in 1:400, polyclonal anti-PP2B (Pan-calcineurin A) antibody (Cell Signaling Technology, Danvers, MA) in 1:400, monoclonal anti-Bcl2 antibody (Upstate, Dundee, Scotland, UK) in 1:500, monoclonal antiintegrin $B 1$ antibody (Chemicon-Millipore, Billerica, MA) in 1:400 and polyclonal anti-integrin $B 3$ antibody (Cell
Signaling Technology, Danvers, MA) in 1:400 dilution were used. After washing for $30 \mathrm{~min}$ with PBST, membranes were incubated with secondary antibodies, anti-rabbit IgG (Bio-Rad Laboratories, CA) in 1:1000 dilution for ERK1/2, calcineurin and integrin B3, anti-mouse IgG (Bio-Rad Laboratories) for $\mathrm{Bcl} 2$, p-ERK $1 / 2$ and integrin $\beta 1$ in $\mathrm{PBS}$ containing $1 \%$ non-fat dry milk for $1 \mathrm{~h}$ at room temperature. Signals were detected by enhanced chemiluminescence (Pierce, Rockford, IL) according to the instruction of the manufacturer.

RT-PCR analysis. For RT-PCR analysis, melanoma cells were washed three times with RNase-free physiological $\mathrm{NaCl}$, then the cultures were snap-frozen in liquid nitrogen and stored at $-70^{\circ} \mathrm{C}$. Cell cultures were dissolved in TRIzol (Applied Biosystems, Foster City, CA), and following addition of $20 \%$ RNase free chloroform (Sigma) samples were centrifuged at $10,000 \mathrm{x}$ g for $15 \mathrm{~min}$ at $4^{\circ} \mathrm{C}$. Samples were incubated in $500 \mu \mathrm{l}$ RNase free isopropanol at $-20^{\circ} \mathrm{C}$ for $1 \mathrm{~h}$, total RNA was dissolved in RNase free water and stored at $-70^{\circ} \mathrm{C}$. The assay mixture for reverse transcriptase reactions contained $2 \mu \mathrm{g}$ RNA, $0.112 \mu \mathrm{M}$ oligo(dT), $0.5 \mathrm{mM}$ dNTP and 200 units of High Capacity RT (Applied Biosystems) in 1X RT buffer. The sequences of primer pairs for polymerase chain reaction were as follows: for calcineurin 5'-TAC CCT GCA GTT TGT GAA TT-3' and 5'-ATA TGT TGA GCA CAT TTA CCA-3', for ERK1/2 5'-CCA GAC CAT GAT CAC ACA GG-3' and 5'-CTC GTC ACT CGG GTC GTA AT-3', for Bcl2 5'-GGG TAC GAT AAC CGG GAG ATA-3' and 5'-GGC CGT ACA GTT CCA AG-3', for integrin 31 5'-GCC TAC TTC TGC ACG ATG-3' and 5'TAA ATG TCT GTG GCT CCC-3', for integrin B3 5'-CGT CCT GAC GCT AAC TGA-3' and 5'-GGT AGT GGA GGC AGA GTA ATG-3', for GAPDH 5'-CCA GAA GAC TGT GGA TGG CC-3' and 5'-CTG TAG CCA AAT TCG TTG TC-3'. At defined annelation degrees 30 cycles were used and PCR products were analysed by electrophoresis in $1.2 \%$ agarose gel containing ethidium bromide (Amresco Inc., Solon, $\mathrm{OH}$ ) and photographed with a gel documentary system (DNR Bio-Imaging Systems Ltd., Jerusalem, Israel).

Calcineurin activity assay. For calcineurin activity assays, cells were harvested and after centrifugation at 10,000 x g for $10 \mathrm{~min}$ at $4^{\circ} \mathrm{C}$, the supernatants were used for enzyme activity measurements. Activity of calcineurin was assayed by the release of ${ }^{32} \mathrm{P}_{\mathrm{i}}$ from ${ }^{32} \mathrm{P}$-labelled protein phosphatase inhibitor-1 as it was described by Yang et al (27) with some modifications (28). Radioactivity was determined by Cerenkov counting in a liquid scintillation counter.

Statistical analysis. Statistical comparisons between control and test samples were analyzed using Student's paired t-test for the cell migration, mitochondrial activity and proliferation assays.

\section{Results}

Both the expression and the activity of calcineurin are higher in the more malignant HT168 cells. As there are no data either on the expression or the enzymatic activity of calcineurin 

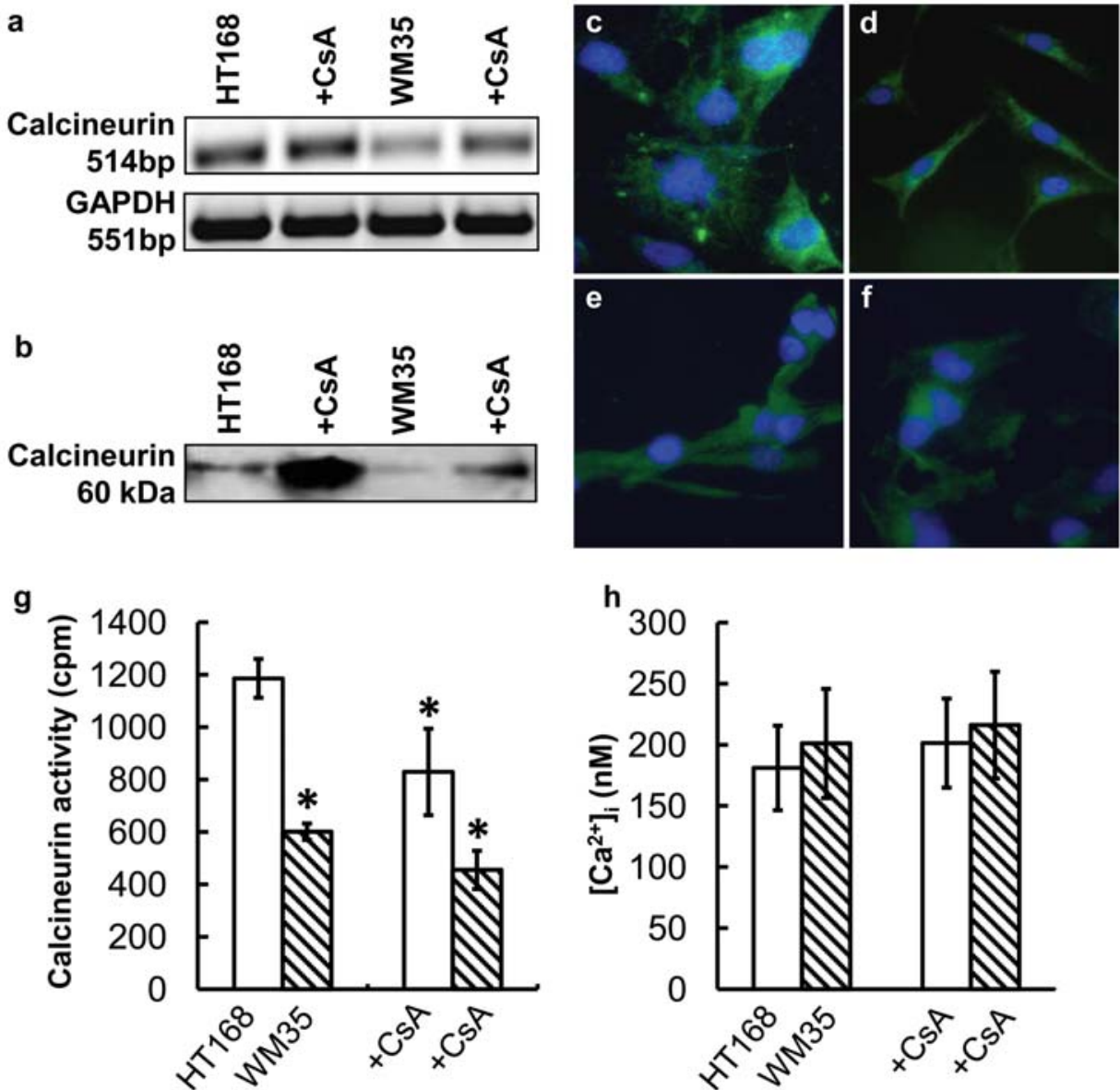

Figure 1. Detection of calcineurin in two different melanoma cell lines. (a) mRNA expression of calcineurin in HT168 and WM35 cells before and after the application of $2 \mu \mathrm{M}$ CsA. GAPDH was used as a control. Representative data of five independent experiments. (b) Protein expression level of calcineurin in untreated control cells and under the effect of $2 \mu \mathrm{M} \mathrm{CsA}$. Representative measurement of five independent experiments. (c-f) Subcellular localization of the catalytic subunit of calcineurin by immunochemistry. Untreated cells of HT168 (c), HT168 cells treated with $2 \mu$ M CsA (d), untreated WM35 cells (e), WM35 cells treated with $2 \mu \mathrm{M}$ CsA (f). Original magnification was x40. Representative photomicrographs of four independent experiments. (g) Enzymatic activity of calcineurin. Asterisks indicate significant $\left({ }^{*} \mathrm{P}<0.05\right)$ decrease of calcineurin activity as compared to the respective control. Representative data of three independent experiments. (h) Free cytosolic $\mathrm{Ca}^{2+}$ level of HT168 and WM35 cells. Basal Ca ${ }^{2+}$ concentration was determined at 70\% confluency in Fura-2-loaded cells. Experiments were carried out after continuous application of $2 \mu \mathrm{M}$ CsA measuring 30 cells in each case. Data represent the mean \pm standard error of the mean of three independent experiments.

in melanoma cells, we first aimed to characterise these parameters in the two cell lines. Cells of both lines expressed mRNA and protein of calcineurin, but HT168 cells exhibited a higher level (Fig. 1a and b) as revealed by RT-PCR and Western blot analyses. Immunocytochemical studies showed diffuse cytoplasmic distribution of the catalytic subunit of calcineurin in both cell lines and a delicate nuclear signal was also visible in the majority of HT168 cells (Fig. 1c and e). Beside its higher protein level, the enzymatic activity of calcineurin was also significantly higher in cells of HT168 (Fig. 1g). Since activity of calcineurin is regulated by $\mathrm{Ca}^{2+} /$ calmodulin, we also determined the basal cytosolic free $\mathrm{Ca}^{2+}$ concentration of melanoma cells. With Fura-2 loading, approximately $180-200 \mathrm{nM}$ intracellular free $\mathrm{Ca}^{2+}$ was detected in both cell lines (Fig. 1h).

CsA influenced expression, activity and distribution of calcineurin. CsA, continuously present in the culture medium, significantly lowered the activity of calcineurin in both cell lines, although the inhibition was more pronounced in HT168 cells (Fig. 1g). Parallel to this finding, we observed a probably compensatory elevation in the expression of calcineurin at mRNA and protein levels (Fig. 1a and b). CsA did not alter the diffuse cytoplasmic distribution of calcineurin as revealed by immunocytochemistry, but the signal was stronger in the cytoplasm of treated cells than in the control ones, furthermore, the granular nuclear signal was diminished by CsA treatment (Fig. 1d and f).

Inhibition of calcineurin alters cell proliferation, viability and cell death. Cell proliferation and mitochondrial activity are sensitive parameters to monitor the cytotoxic effects of any pharmacological interventions. Both proliferation and mitochondrial activity were higher in HT168 cells than in WM35 cells under control conditions (Fig. 2a and b). CsA treatment significantly reduced proliferation in both cell lines, although HT168 cells responded more prominently than WM35 (Fig. 2a). Furthermore, repression of mitochondrial activity was also observed indicating the reduced viability of cells. The decrease was significant in HT168 cells and only non-significant effect was detected in WM35 cells (Fig. 2b). CsA caused moderate increase of cell death 
a

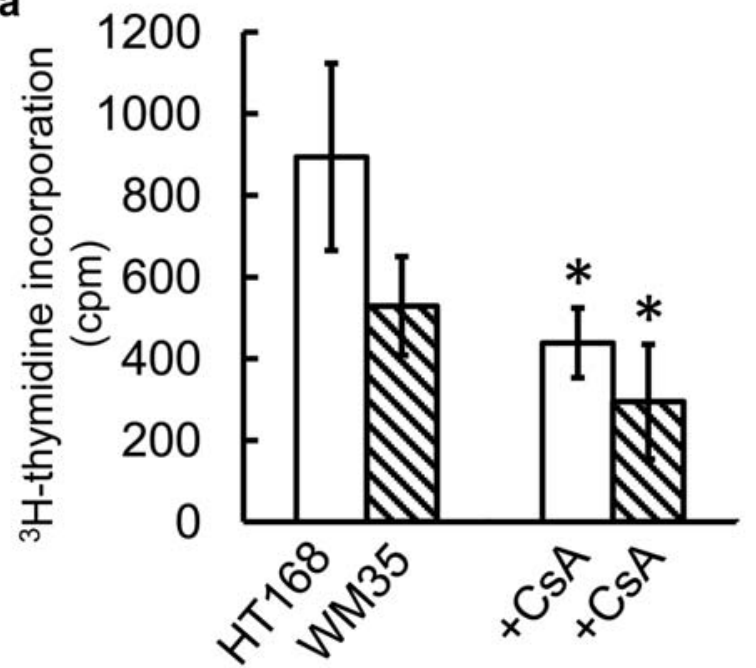

C
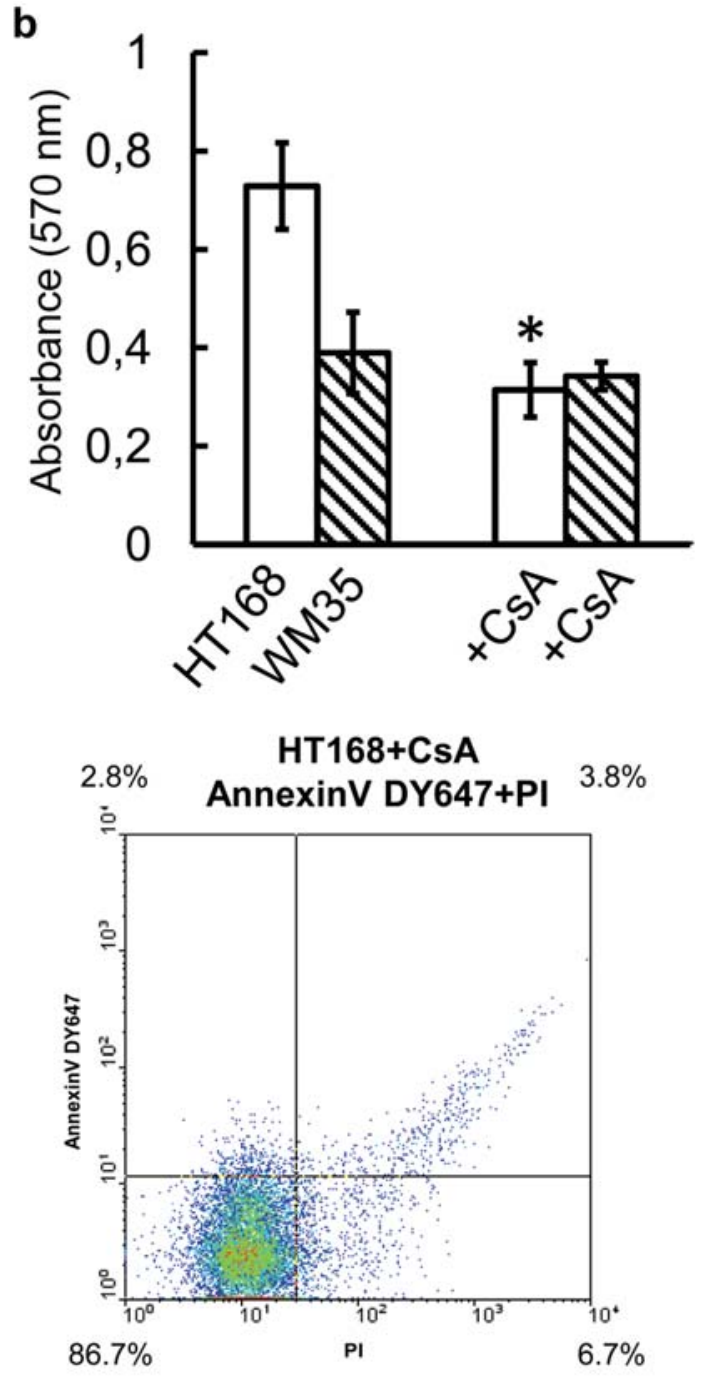

$86.7 \%$

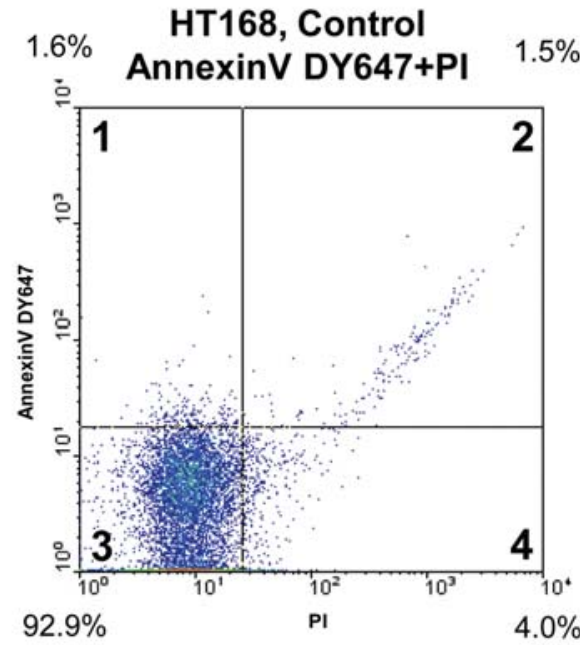

WM35, Control
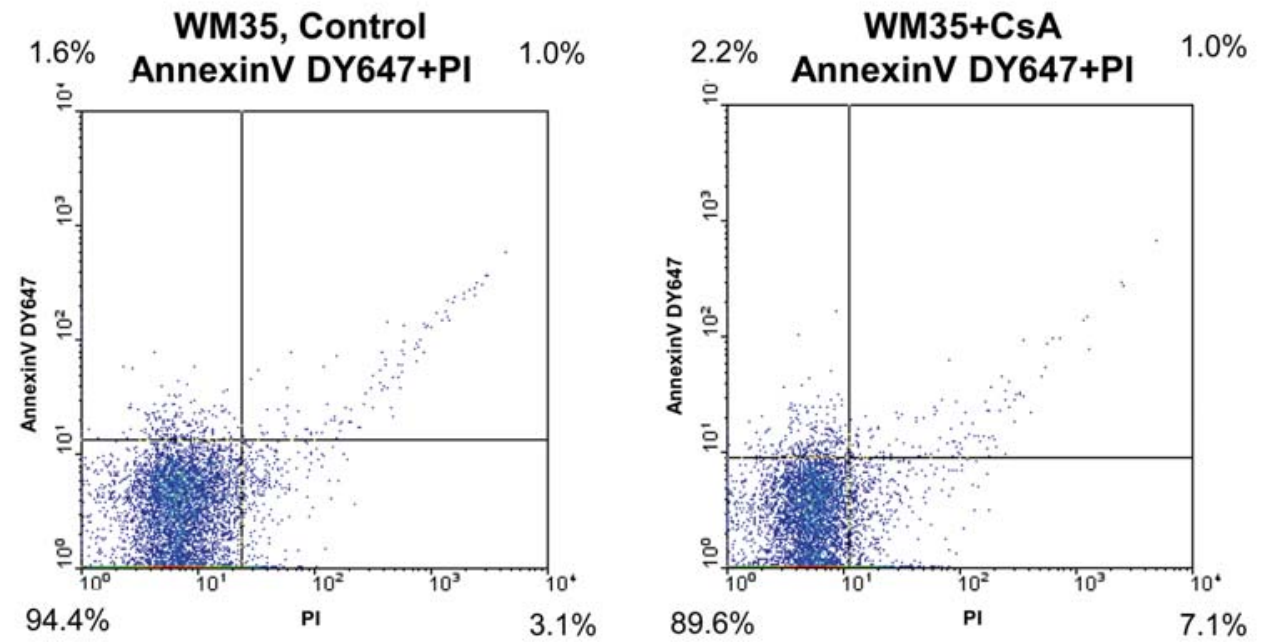

Figure 2. Effect of CsA on proliferation rate (a) and mitochondrial activity (b) of melanoma cell lines. Proliferation and mitochondrial activity were assessed by ${ }^{3} \mathrm{H}$-thymidine incorporation and MTT assay, respectively. Assays were carried out 2 days after continuous treatment by $2 \mu \mathrm{M}$ CsA. Data represent the mean \pm standard error of the mean of three independent experiments. Asterisks indicate significant decrease $\left({ }^{*} \mathrm{P}<0.05\right)$ in ${ }^{3} \mathrm{H}$-thymidine incorporation or significant decrease $\left({ }^{*} \mathrm{P}<0.05\right)$ in cellular viability as compared to the respective control. (c) Apoptotic and necrotic effect of CsA treatment determined by the detection of Annexin V DY647 and propidium-iodide with FACS analysis. Quadrant 1 represents cells binding Annexin V DY647 (i.e. early apoptotic cells), quadrant 4 contains propidium iodide stained cells (i.e. necrotic cells), quadrant 2 shows the combination of the two effects, and quadrant 3 represents living cells. Representative data of three independent experiments.

as it was detected by FACS analyses using Annexin V or propidium iodide incorporation methods (Fig. 2c).
Opposite effects of CsA on fibronectin-guided migration of HT168 and WM35 cells. Investigation of a chemoattractant- 


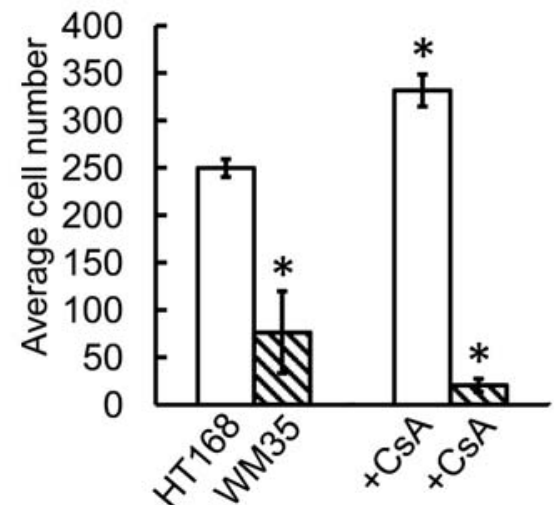

Figure 3. Effect of $2 \mu \mathrm{M}$ CsA on the migration ability of melanoma cells Fibronectin was used as a chemoattractant. Data represent the mean \pm standard error of the mean of five independent experiments and are given in the average cell number of migrated cells. Asterisks indicate significant $\left({ }^{*} \mathrm{P}<0.05\right)$ decrease or increase in the number of migrated cells as compared to the respective control.

directed migration of tumour cells is an accepted in vitro model to simulate and estimate the invasiveness and mobility in tissues. As fibronectin is present both in the basement membrane of epidermis and in the extracellular matrix of dermal connective tissue, as well as in the majority of tumour matrices, it seemed to be a good candidate to use as a chemoattractant in Boyden chamber for migration assays of melanoma cells. Significantly higher number of HT168 cells migrated through the polycarbonate membrane toward fibronectin under control conditions compared to WM35 cells (Fig. 3). Application of CsA in the culturing medium of melanoma cells prior to the migration assay had opposite effects; migration of HT168 cells was facilitated, while that of WM35 cells was inhibited as revealed by counting of migrated cells (Fig. 3). An identical effect was observed when CsA was present in the culturing medium during the migration assay (data not shown).

CsA modulates cell shape and actin organization of melanoma cells. Simultaneous changes of cell shape and reorganization of actin cytoskeleton are key elements in the migration of cells. Since inhibition of calcineurin had significant effect on fibronectin directed migration of melanoma cells, we investigated the morphology and the organization of actin network when CsA was applied. Untreated HT168 and WM35 cells exhibited pronounced morphological differences. High cellular polymorphism including giant cells with probably polyploid nuclei were characteristic in the more malignant HT168, whereas more uniform spindleshaped and multipolar cells were visible in the less malignant cell line (Fig. 4a and c). CsA caused dramatic morphological changes in both cell lines. The majority of cells in HT168 became more elongated and gained longer processes, WM35 cells lost their long extensions and became more compact under the effect of CsA. Additionally, cytoplasm of WM35 cells became somehow 'foamy-like'. Furthermore, compaction of nuclei and a decreased number of nucleoli were observed in both cell lines (Fig. 4b and d). Actin network of untreated HT168 cells formed well defined stress fibers which
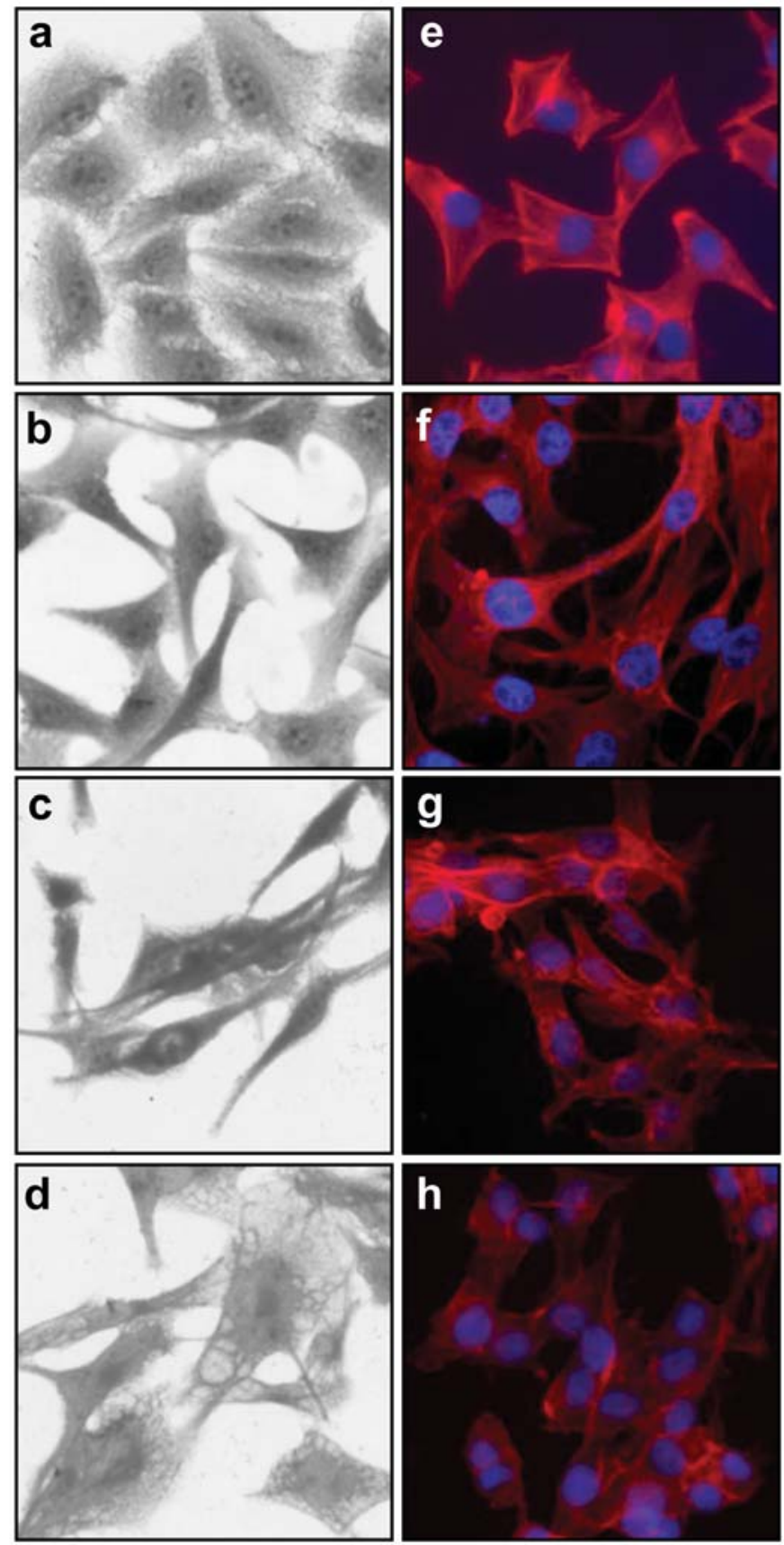

Figure 4. Melanoma cells visualized with haematoxylin and eosin staining. HT168 (a), HT168+CsA (b), WM35 (c) and WM35+CsA (d). Original magnification was $\mathrm{x} 40$. TRITC-phalloidin was used to visualize the actin skeleton system of melanoma cells. HT168 (e), HT168+CsA (f), WM35 (g) and WM35+CsA (h). Nucleus was visualized with DAPI. Original magnification was $\mathrm{x} 40$. Representative photomicrographs of five independent experiments.

became thicker and more developed in the presence of CsA (Fig. 4e and f). Untreated WM35 cells did not exhibit pronounced actin cables and only a few delicate stress fibers appeared under the effect of CsA (Fig. $4 \mathrm{~g}$ and $\mathrm{h}$ ).

$\beta 1$ and $\beta 3$ integrin, $B c l-2$ and ERK1/2 expressions in melanoma cell lines. As cells can attach to fibronectin mainly via $\alpha 5 \beta 1$ and $\alpha 5 \beta 3$ integrins, we investigated the expression of $B 1$ and $B 3$ integrin subunits in melanoma cells. We found that both cell lines express more $B 3$ than $\beta 1$ subunit proteins 

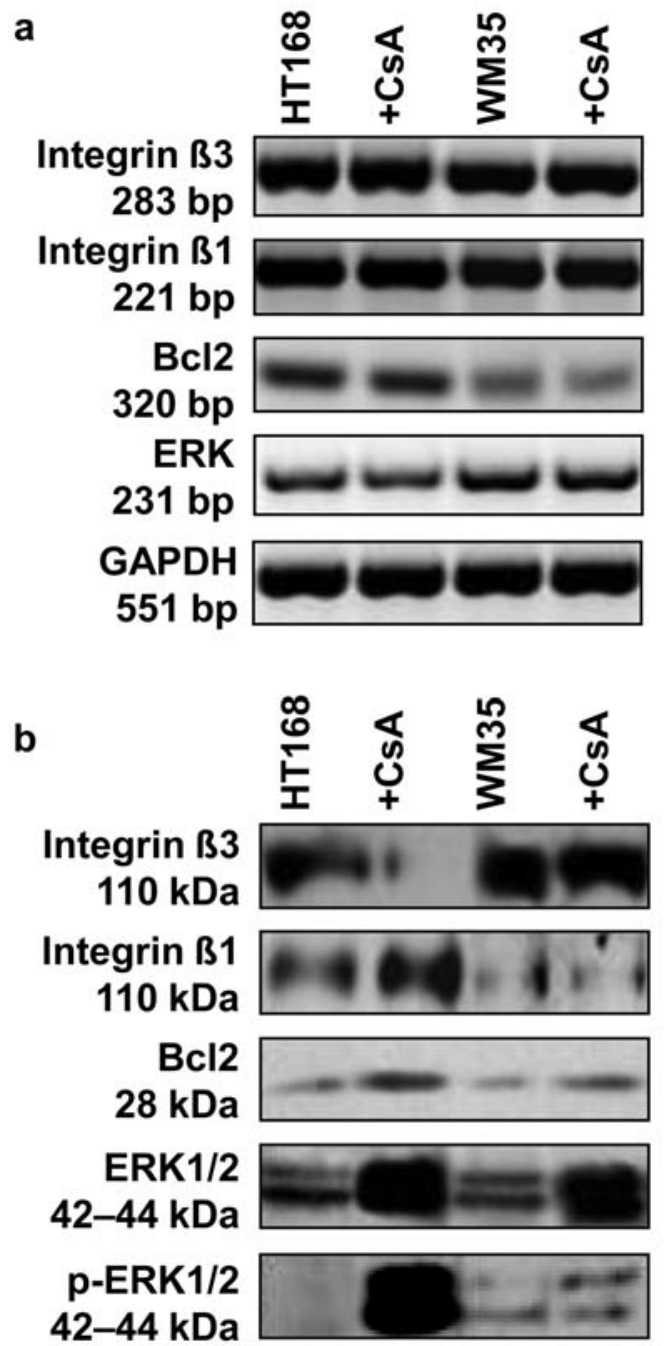

Figure 5. $B 1$ and $B 3$ integrin, Bcl-2 and ERK1/2 expressions in melanoma cell lines. (a) Effect of $2 \mu \mathrm{M}$ CsA on the mRNA expression of integrin $B 3$ integrin $\beta 1, \mathrm{bcl} 2$ and ERK. GAPDH was used as a control. Representative measurement of five independent experiments. (b) Protein expression of integrin $\beta 3$, integrin $\beta 1, \mathrm{Bcl} 2$, ERK1/2 and phosphorylation level of ERK1/2 as revealed by Western blot analysis. Representative data of five independent experiments.

and the difference was very prominent in the case of WM35 cells (Fig. 5b). Treatment of cells with CsA resulted in opposite effects in the two different cell lines. WM35 cells did not show any significant change in the protein level of either $\beta 1$ or $\beta 3$ subunits, while cells of HT168 did change their protein expression pattern: stronger $B 1$ and weaker $B 3$ protein signals were detected as compared to the untreated cells (Fig. 5b). None of the afore-mentioned differences were detected at the mRNA level (Fig. 5a).

Apoptosis resistance is one of the worst biological properties of melanoma cells, therefore we investigated the expression of the anti-apoptotic Bcl-2 and also the expression and phosphorylation levels of ERK1/2. The latter molecule is widely accepted as one of the most important factors responsible for the apoptosis resistance of melanoma cells (29). Similarly to the results observed for integrins, the changes of Bcl-2 or ERK1/2 were only detected at protein levels, mRNA expressions exhibited no significant alterations
(Fig. 5a). Despite this fact, we detected differences either in the protein level or in the phosphorylation status of ERK1/2 in control and CsA-treated cells. We did not detect any significant difference in the expression levels of ERK1/2 of the two cell lines under control conditions. Inhibition of calcineurin resulted in a significant elevation of unphosphorylated ERK1/2 in both cell lines and an extremely pronounced level of dual-phosphorylated ERK1/2 appeared in HT168 cells (Fig. 5b). Bcl-2 protein was somewhat less expressed by WM35 cells than that of HT168 cells under control conditions, but both cell lines responded to CsA treatment with a slight increase of $\mathrm{Bcl}-2$ protein level (Fig. 5b).

\section{Discussion}

Our data provide evidence for the presence and the activity of calcineurin, furthermore, some possible targets of the enzyme are also suggested in HT168 and WM35 human melanoma cell lines. The two cell lines did not exhibit pronounced differences either in mRNA or protein levels of calcineurin, but a much higher enzyme activity was detected in HT168 cells. Activity of calcineurin is dependent on changes of the intracellular Ca-concentration. The basal cytosolic-free Ca-concentration was found 180-200 nM in both cell lines, which value is in line with that of reported by Hodgson and Dong (30) in A2058, the parental cell line of HT168. The half-maximal activation of calcineurin could require higher Ca-concentration (400-600 nM), at least in enzyme activity assay (31). Therefore, we may suppose periodic activation of different $\mathrm{Ca}$-channels either in the plasma membrane or in the endoplasmic reticulum of melanoma cells, since oscillations of intracellular Ca-concentration are also reported to sensitize cells to Ca-signalling (32). Another possibility is that $\mathrm{Ca}$-independent regulatory molecules of calcineurin, such as calcipressin, binding to the regulatory subunit of calcineurin or cabin 1 interacting with activated calcineurin may be involved in the modulation of its activity in melanoma cells (33).

CsA is perhaps the best known pharmacological inhibitor of calcineurin, thus we applied this drug to investigate the possible effects of calcineurin in melanoma cells. Some cellular functions were modulated in opposing directions in the two cell lines. Viability assays detected significant cytotoxicity on HT168 cells in the presence of CsA, while WM35 cells did not respond so. This observation may reflect that more malignant melanoma cells are more sensitive to the inhibition of calcineurin function. In some aspects the two cell lines responded to CsA treatment similarly. Activity of calcineurin was lowered by $30-50 \%$, proliferation of melanoma cells was attenuated by $50 \%$ and the rate of cell death was moderately affected. Furthermore, CsA caused pronounced alterations in the morphology of both cell lines, although the direction of these changes proved to be different. HT168 cells became more elongated, while WM35 cells lost their processes and became rather polygonal. This observation is partly in line with those described by Hojo et al (34) who found that CsA treatment of pulmonary adenocarcinoma cell line A-549 resulted in morphological changes including formation of membrane ruffling and numerous pseudopodial 
protrusions. We also observed that nuclei of cells became more compact and less nucleoli were visible in each individual nucleus.

The profound effect of CsA treatment on the morphology of cells of both cell lines raised the possibility of the modulation of mobility/invasiveness of melanoma cells. It is well known that mobility of different cells including those of malignant phenotype is promoted by multiple factors such as adhesion to the extracellular matrix molecules or changes of intracellular Ca-concentration $(18,35)$. In some cases simultaneous involvement of the two events were also reported, e.g. type IV collagen stimulated intracellular calcium in the A2058 human melanoma cell line (36), however, fibronectin failed to induce the same change. On the other hand, results of Hodgson and Dong (30) elucidated an other aspect of the relationship of adhesion/migration and intracellular Ca. Type IV collagen guided migration of A2058 cells was found effectively abrogated by increased intracellular calcium concentration. Nonetheless, both groups $(30,36)$ have suggested the implication of calcineurin in the altered guided migration of melanoma cells. Therefore, we investigated the effect of the inhibition of calcineurin on the fibronectin guided migration of the two melanoma cell lines. We found that CsA had pronounced promoting effect on the chemotaxis of HT168 cells. On the other hand, WM35 cells were significantly inhibited in their migration ability by this compound. Influence of CsA on the migration and the invasiveness of several tumour types was recently investigated yielding different results. Sliwa et al (37) reported inhibition of migration of glioblastoma cells treated by CsA and Yiu and Toker (38) found that CsA inhibited the migration of breast cancer cells in an NFAT- and COX-2-dependent manner. On the contrary, motility and invasiveness of lung adenocarcinoma cell line was stimulated by CsA (34). These contradictory observations might be explained if we suppose a cell type- and progression-dependent influence of calcineurin on the migration ability of different tumour cells.

There are several observations describing the role of calcineurin in the reorganization of actin network of different cell types, such as neurons (39) or neutrophil granulocytes $(40,41)$. We also found that beside changes in morphology of melanoma cells, CsA caused pronounced alterations of actin network in HT168 cells. The opposite response of the two cell lines in changes of morphology, actin reorganization and chemotaxis may imply the possibility of different target molecules of calcineurin in the two different phases of progression of melanoma.

Adhesion to the tumour matrix molecules and the chemotaxis of malignant cells are influenced by the expression pattern of receptors to extracellular matrix molecules, such as integrins (42). Integrin signalling of melanoma cells is extensively investigated (43) and a wide range of different integrins is referred to be present in them. According to our Western blot analysis, both cell lines express more $B 3$ than $\beta 1$ integrin subunits. It is accepted that melanocytes do not express $\beta 3$ but possess $\beta 1$ integrins and during development of melanoma, the appearance of $\beta 3$ integrins is a specific marker of transition from radial growth phase to vertical growth phase (44). CsA altered the integrin expression profile in the two cell lines: HT168 cells switched from $B 3$ to $\beta 1$ integrins, while WM35 cells kept expressing B3 integrins. To find the biological implication of this opposite response requires further investigations, particularly if we consider the fact that fibronectin guided migration of HT168 cells was stimulated, while that of WM35 cells was inhibited by CsA. Nonetheless, it is possible that the difference in the change of the integrin pattern of melanoma cells in response to CsA treatment may reflect the involvement of malignancy stagedependent role of calcineurin in the regulation of fibronectin guided migration of melanoma cells.

Beside their high motility, another biological property providing poor prognosis of melanoma is the high resistance of the melanoma cells to apoptosis. Sustained overactivation of MAPKK/ERK pathway is regarded as one of the factors which protect melanoma cells against apoptosis inducing chemotherapies. In human keratinocytes, CsA is described to decrease DNA repair and apoptosis following UV irradiation (8) and indeed, we found that CsA did not cause significant cell death either in HT168 or WM35 cells. Parallel to this, expression and phosphorylation of ERK1/2 was extremely elevated in CsA treated cells. Moreover, CsA caused increased expression of anti-apoptotic $\mathrm{Bcl} 2$. These data support the idea that calcineurin might be an important factor in the regulation of apoptosis in melanoma cells, although inhibition of calcineurin alone did not cause significant alteration of cell death. Nonetheless, CsA has been described to augment the apoptotic effect of taxol in urinary bladder cancer cells (45) and modulation of intracellular calcium level with depleting intracellular Ca-stores also caused a calcineurin-dependent apoptosis in prostatic cancer cells (46).

In conclusion, calcineurin plays multiple roles in the different cellular functions of the two human melanoma cell lines investigated. Our observations may point out the involvement of calcineurin in the malignant transformation of melanocytes in vivo, which is independent from the alteration of T-lymphocyte function. This idea is supported by data of Hojo et al (34), drawing our attention to the possible immunosuppression-independent role of calcineurin in the development of malignant phenotype of different cell types.

\section{Acknowledgements}

The authors thank Mrs. Krisztina Bíró of the Department of Anatomy, Krisztina Körmendi, Csilla Somogyi and Renáta Süto medical students of Medical and Health Science Centre, University of Debrecen, Hungary for their skilful and excellent technical assistance. This work was supported by grants from the Hungarian Science Research Fund (OTKA K60620 and OTKA T49151) and the Hungarian Ministry of Health (ETT 083/2006).

\section{References}

1. Sim AT: The regulation and function of protein phosphatases in the brain. Mol Neurobiol 5: 229-246, 1991.

2. Clipstone NA and Crabtree GR: Identification of calcineurin as a key signalling enzyme in T-lymphocyte activation. Nature 357: 695-697, 1992.

3. Emmel EA, Verweij CL, Durand DB, Higgins KM, Lacy E and Crabtree GR: Cyclosporin A specifically inhibits function of nuclear proteins involved in T cell activation. Science 246: 1617-1620, 1989. 
4. Breuer K, Werfel T and Kapp A: Allergic manifestations of skin diseases - atopic dermatitis. Chem Immunol Allergy 91: 76-86, 2006

5. Rustin MH: The safety of tacrolimus ointment for the treatment of atopic dermatitis: a review. Br J Dermatol 157: 861-873, 2007.

6. Herman S, Rogers HD and Ratner D: Immunosuppression and squamous cell carcinoma: a focus on solid organ transplant recipients. Skinmed 6: 234-238, 2007.

7. Mammucari C, Tommasi DV, Sharov AA, Neilson J, Havrda MC, Roop DR, Botchkarev VA, Crabtree GR and Dotto GP: Integration of Notch 1 and calcineurin/NFAT signaling pathways in keratinocyte growth and differentiation control. Dev Cell 8: 665-676, 2005.

8. Yarosh DB, Pena AV, Nay SL, Canning MT and Brown DA: Calcineurin inhibitors decrease DNA repair and apoptosis in human keratinocytes following ultraviolet B irradiation. J Invest Dermatol 125: 1020-1025, 2005.

9. Hartmann A, Brocker EB and Becker JC: Hypopigmentary skin disorders: current treatment options and future directions. Drugs 64: 89-107, 2004.

10. Smit NP, van Rossum HH, Romijn FP, Sellar KJ, Breetveld M, Gibbs S and van PJ: Calcineurin activity and inhibition in skin and (epi)dermal cell cultures. J Invest Dermatol 128: 1686-1690, 2008.

11. Haass NK, Smalley KS and Herlyn M: The role of altered cell-cell communication in melanoma progression. J Mol Histol 35: 309-318, 2004

12. Oka $\mathrm{M}$ and Kikkawa U: Protein kinase $\mathrm{C}$ in melanoma. Cancer Metastasis Rev 24: 287-300, 2005.

13. Mantovani G, Bondioni S, Lania AG, Rodolfo M, Peverelli E Polentarutti N, Veliz RT, Ferrero S, Bosari S, Beck-Peccoz P and Spada A: High expression of PKA regulatory subunit $1 \mathrm{~A}$ protein is related to proliferation of human melanoma cells Oncogene 27: 1834-1843, 2008.

14. Fecher LA, Amaravadi RK and Flaherty KT: The MAPK pathway in melanoma. Curr Opin Oncol 20: 183-189, 2008.

15. Haluska F, Pemberton T, Ibrahim N and Kalinsky K: The RTK/RAS/BRAF/PI3K pathways in melanoma: biology, small molecule inhibitors, and potential applications. Semin Oncol 34: 546-554, 2007.

16. Kondapalli L, Soltani K and Lacouture ME: The promise of molecular targeted therapies: protein kinase inhibitors in the treatment of cutaneous malignancies. J Am Acad Dermatol 53: 291-302, 2005.

17. Gray-Schopfer V, Wellbrock C and Marais R: Melanoma biology and new targeted therapy. Nature 445: 851-857, 2007.

18. Cox JL, Lancaster T and Carlson CG: Changes in the motility of B16F10 melanoma cells induced by alterations in resting calcium influx. Melanoma Res 12: 211-219, 2002.

19. Glass-Marmor L, Penso J and Beitner R: $\mathrm{Ca}^{2+}$-induced changes in energy metabolism and viability of melanoma cells. Br J Cancer 8: 219-224, 1999.

20. Ladanyi A, Timar J, Paku S, Molnar G and Lapis K: Selection and characterization of human melanoma lines with different liver-colonizing capacity. Int J Cancer 46: 456-461, 1990.

21. Herlyn M: Human melanoma: development and progression. Cancer Metastasis Rev 9: 101-112, 1990.

22. Sainte-Marie G: A paraffin embedding technique for studies employing immunofluorescence. J Histochem Cytochem 10 250-256, 1962.

23. Wulf E, Deboben A, Bautz FA, Faulstich $\mathrm{H}$ and Wieland T: Fluorescent phallotoxin, a tool for the visualization of cellular actin. Proc Natl Acad Sci USA 76: 4498-4502, 1979.

24. Albini A, Allavena G, Melchiori A, Giancotti F, Richter H, Comoglio PM, Parodi S, Martin GR and Tarone G: Chemotaxis of $3 \mathrm{~T} 3$ and SV3T3 cells to fibronectin is mediated through the cell-attachment site in fibronectin and a fibronectin cell surface receptor. J Cell Biol 105: 1867-1872, 1987.

25. Koopman G, Reutelingsperger CP, Kuijten GA, Keehnen RM Pals ST and van Oers MH: Annexin V for flow cytometric detection of phosphatidylserine expression on B cells undergoing apoptosis. Blood 84: 1415-1420, 1994.
26. Grynkiewicz G, Poenie M and Tsien RY: A new generation of $\mathrm{Ca}^{2+}$ indicators with greatly improved fluorescence properties. J Biol Chem 260: 3440-3450, 1985.

27. Yang SD, Tallant EA and Cheung WY: Calcineurin is a calmodulin-dependent protein phosphatase. Biochem Biophys Res Commun 106: 1419-1425, 1982.

28. Zakany R, Szijgyarto Z, Matta C, Juhasz T, Csortos C, Szucs K, Czifra G, Biro T, Modis L and Gergely P: Hydrogen peroxide inhibits formation of cartilage in chicken micromass cultures and decreases the activity of calcineurin: implication of ERK1/2 and Sox9 pathways. Exp Cell Res 305: 190-199, 2005.

29. Mirmohammadsadegh A, Mota R, Gustrau A, Hassan M, Nambiar S, Marini A, Bojar H, Tannapfel A and Hengge UR: ERK $1 / 2$ is highly phosphorylated in melanoma metastases and protects melanoma cells from cisplatin-mediated apoptosis. J Invest Dermatol 127: 2207-2215, 2007.

30. Hodgson $\mathrm{L}$ and Dong $\mathrm{C}$ : $\left[\mathrm{Ca}^{2+}\right] \mathrm{i}$ as a potential downregulator of alpha2beta1-integrin-mediated A2058 tumor cell migration to type IV collagen. Am J Physiol Cell Physiol 281: C106-C113, 2001.

31. Stemmer PM and Klee CB: Dual calcium ion regulation of calcineurin by calmodulin and calcineurin B. Biochemistry 33: 6859-6866, 1994.

32. Dolmetsch RE, Lewis RS, Goodnow CC and Healy JI: Differential activation of transcription factors induced by $\mathrm{Ca} 2+$ response amplitude and duration. Nature 386: 855-858, 1997.

33. Parry RV and June CH: Calcium-independent calcineurin regulation. Nat Immunol 4: 821-823, 2003.

34. Hojo M, Morimoto T, Maluccio M, Asano T, Morimoto K, Lagman M, Shimbo T and Suthanthiran M: Cyclosporine induces cancer progression by a cell-autonomous mechanism. Nature 397: 530-534, 1999.

35. Hendey B and Maxfield FR: Regulation of neutrophil motility and adhesion by intracellular calcium transients. Blood Cells 19: 143-161, 1993.

36. Savarese DM, Russell JT, Fatatis A and Liotta LA: Type IV collagen stimulates an increase in intracellular calcium. Potential role in tumor cell motility. J Biol Chem 267: 21928-21935, 1992.

37. Sliwa M, Markovic D, Gabrusiewicz K, Synowitz M, Glass R, Zawadzka M, Wesolowska A, Kettenmann H and Kaminska B: The invasion promoting effect of microglia on glioblastoma cells is inhibited by cyclosporin A. Brain 130: 476-489, 2007.

38. Yiu GK and Toker A: NFAT induces breast cancer cell invasion by promoting the induction of cyclooxygenase-2. J Biol Chem 281: 12210-12217, 2006.

39. Halpain S, Hipolito A and Saffer L: Regulation of F-actin stability in dendritic spines by glutamate receptors and calcineurin. J Neurosci 18: 9835-9844, 1998.

40. Lawson MA and Maxfield FR: $\mathrm{Ca}(2+)-$ and calcineurin-dependent recycling of an integrin to the front of migrating neutrophils. Nature 377: 75-79, 1995

41. McMorrow T, Gaffney MM, Slattery C, Campbell E and Ryan MP: Cyclosporine A induced epithelial-mesenchymal transition in human renal proximal tubular epithelial cells. Nephrol Dial Transplant 20: 2215-2225, 2005.

42. Mostafavi-Pour Z, Askari JA, Parkinson SJ, Parker PJ, Ng TT and Humphries MJ: Integrin-specific signaling pathways controlling focal adhesion formation and cell migration. J Cell Biol 161: 155-167, 2003.

43. Kuphal S, Bauer R and Bosserhoff AK: Integrin signaling in malignant melanoma. Cancer Metastasis Rev 24: 195-222, 2005.

44. Natali PG, Nicotra MR, Di FF and Bigotti A: Expression of fibronectin, fibronectin isoforms and integrin receptors in melanocytic lesions. Br J Cancer 71: 1243-1247, 1995.

45. Nomura T, Yamamoto H, Mimata H, Shitashige M, Shibasaki F, Miyamoto E and Nomura Y: Enhancement by cyclosporin A of taxol-induced apoptosis of human urinary bladder cancer cells. Urol Res 30: 102-111, 2002.

46. Tombal B, Weeraratna AT, Denmeade SR and Isaacs JT: Thapsigargin induces a calmodulin/calcineurin-dependent apoptotic cascade responsible for the death of prostatic cancer cells. Prostate 43: 303-317, 2000. 